\title{
Assessment of Aqueous Leave Extract of Gnetum africanum (AFANG) on the Testis of Adult Male Wistar Rats
}

\author{
Kebe E Obeten ${ }^{1}$, Victor A Fischer ${ }^{2}$, Tangban C Nyen ${ }^{1}$ and Adoga M Ogbiji ${ }^{3}$ \\ ${ }^{1}$ Department of Human Anatomy and Forensic Anthropology, Cross River University of Technology, Calabar, Nigeria \\ ${ }^{2}$ Department of Anatomy, University of Calabar, Calabar, Nigeria \\ ${ }^{3}$ Department of Radiography and Radiological Science, University of Calabar, Calabar, Nigeria \\ *Corresponding Author: Kebe E Obeten, Department of Human Anatomy and Forensic Anthropology, Cross River University of \\ Technology, Calabar, Nigeria.
}

Received: July 02, 2019; Published: July 10, 2019

DOI: 10.31080 /ASPS.2019.03.0334

\begin{abstract}
Effect of aqueous leave extract of Gnetum africanum (afang) in adult male Wistar rats was studied. Eighteen (18) adult Wistar rats weighing between $80-150 \mathrm{~g}$ were allotted into three groups of six rats each. Group 1 was the control group, given normal rat chew and distilled water, while groups 2 and 3 served as the experimental groups treated with $300 \mathrm{mg} / \mathrm{kg}$ body weight and $500 \mathrm{mg} /$ $\mathrm{kg}$ body weight of the extract respectively, orally for 21 days. Animals were sacrificed under chloroform inhalation, testes removed for histological observation using H\&E stain and DNA distribution using Feulgen stain. Epididymal semen was used semen analysis. Result showed significant $(\mathrm{p}<0.05)$ increase in animals' final body weights. No significant difference in the sperm motility of all experimental animals, but significant $(\mathrm{p}<0.05)$ decrease in the sperm vitality and morphology of animals in low and high dose groups when compared to the control was observed. There was normal cytoarchitecture of the testis of animals in control group. Meanwhile low dose group showed sertoli cell tumors and extensive areas of prognosis of sclerosis. However, the high dose group showed a general testicular regression syndrome which is an indication of testicular infarct. Histochemical studies showed moderately stained magenta colour in the normal and low dose groups indicating the presence of DNA. The colour intensity was deep in the high dose group revealing increased DNA. Hence, study suggests consumption of Gnetum africanum, although may lead to increase in testicular DNA, may as well cause deleterious effects on the histology of the testes with reduction in semen quality.
\end{abstract}

Keywords: Gnetum africanum; Wistar Rat; DNA; Testes; Histochemical

\section{Introduction}

Plants are mainly multicellular, predominantly photosynthetic eukaryotes of the kingdom plantae. Plants paly many roles in culture, they are used as ornament and until recently and in great variety they have served as source of most medicines [1]. According to Anthony., et al. [2], due to recent increase evidences about the effectiveness of herbal medicines being widely available and affordable, herbal practitioners claim to have cure for various ailments, including infertility irrespective of the cause of the disease. Some medicinal plants are used as fertility enhancing agents as well as aphrodisiac to relieve sexual dysfunction (Tekwe., et al. 2003). Some of these plants that exhibit medicinal properties have been known to help in stabilizing different internal organs in animals, while other have side-effect on the organs due to varying amount of toxic matter present in such plants (Styslinger, 2008).
Infertility refers to the inability to conceive after having regular unprotected sex [3]. It can also refer to the biological inability of an individual to contribute to conception, or to a female who cannot carry a pregnancy to full term. Infertility and reproductive abnormalities affect about eighty million persons throughout the world [4]. It is a universal circumstance that exceeds human race and tribe, often caused by certain phytochemicals and drugs that alter physiological processes in man and animals [5].

Afang (Gnetum africanum) is a medicinal plant usually found in humid tropical forest regions of Cameroon, Gabon, Angola as well as Nigeria, which does not grow well in direct sun light and can be found climbing on middle and under-story tress (Tekwe., et al. 2003). Gnetum africanum has various uses among which the leaves are used as vegetable for soups and stews, commonly called eru soup or afang soup (Tekwe., et al. 2003). Medicinally, the leaves 
are used as remedy for nausea, sore throats and for warts dressing, while the steam may be eaten to reduce pain during childbirth (Styslinger, 2008). Gnetum africanum has numerous common names and is grown in various countries across Africa including; Cameroon (Eru, Okok, m'fumbua, or fumbua), Angola (koko), Nigeria (Ukazi or Afang), Gabon (koko), Central African Republic (Koko), Congo (Koko) and the Democratic Republic of Congo (m'fumbua or fumba).

The testes are a paired and primary organ of the male reproductive system. The term "testis" was derived from a Latin wordtesticulus, which means "witness of virility" [6]. The testes (testissingular) are homologous to the ovaries in females and they are both part of the male and female reproductive axes respectively. The testes function primarily in sperm production (spermatogenesis) and hormone production, primarily, testosterone [7]. These functions are both regulated by gonadotropins which are produced and released by the adenohypophysis, under the influence of gonadotropin-releasing hormone $(\mathrm{GnRH})$ secreted by the hypothalamus. The gonadotropes produces LH and FSH. LH stimulates the testis to secrete testosterone while FSH is needed for spermatogenesis to take place.

\section{Materials and Method}

Ethical consideration

This was obtained from the Ethical Board of the Faculty of Basic Medical Sciences Cross River University of Technology with Ref No: $22 / 2018$.

\section{Extract preparation}

Gnetum africanum leaves were gotten from Ikom four corners main market of Ikom Local Government Area of Cross River State, Nigeria. The leaves were properly identified and authenticated by Mr. Edem of the herbarium unit, University of Calabar-Nigeria with specimen no: HB3556/18. The leaves were plucked and dried at a room temperature of about $27^{\circ} \mathrm{C}$ for about four weeks. The leaves were blended to fine powder using a grinding machine. The blended sample of gnetum africanum leaf powder was weighed using digital weighing balance and was found to be weighing $120 \mathrm{~g}$. The blended leaf was macerated with $1000 \mathrm{mls}$ distilled water and the mixture was left four 48 hours at $20^{\circ} \mathrm{C}$ mixture was filtered, after which cheese cloth was used for filtration followed by filter paper (Whatman No. 1).

\section{Experimental animals}

Eighteen (18) fit and matured adult male Wistar rats weighing between 80 -150g were purchased from the animal house of the Department of Human Anatomy, Cross River University of Technology, Okuku. The entire animals were kept in aluminum cages covered with wire mesh in standard laboratory environment. All animals were given water and commercial feed and allowed to rest and acclimatize for two weeks before commencement of experiment.

\section{Experimental design and procedure}

The eighteen (18) animals were allotted to three groups consisting of six rats each. Animals in group 1 served as the control group, fed with normal rat chew and distilled water, while groups 2 and 3 served as the experimental groups treated with Gnetum africanum leaf extract, orally for 21 days. Group 2 (low dose group) animals were treated with $300 \mathrm{mg} / \mathrm{kg}$ body weight of Gnetum africanum leaf extract, while group 3 (high dose group) animals were treated with $500 \mathrm{mg} / \mathrm{kg}$ body weight of the extract.

\section{Termination of experiment}

At the end of experiment, all animals were sacrificed under chloroform anesthesia and the testis surgically removed and fixed in bouins fluid for 24 hours for histological and histochemical studies. The caudal epididymides were separated from the testis and processed immediately for epididymal sperm parameters.

\section{Semen analysis}

Semen was obtained from the cauda epididymis by scrapping the lumen into a tube prewarmed in water bath at $50-60^{\circ} \mathrm{C}$. a drop of this specimen was placed on a slide in the chamber and covered with a cover glass. The following parameters; sperm motility, vitality and morphology were determined using the Makler counting chamber with Olympus microscope.

\section{Histological examination of the testis}

- Reagents: Haematoxylin, eosin, xylene, alcohol and chloroform

- $\quad$ Procedure: Tissue blocks were sectioned at 5microns using a microtome. Sections were brought to xylene for two minutes per two changes. The xylene was cleared in 95\% alcohol for one minute per two changes and then in $70 \%$ alcohol for another one minute. This was then hydrated in running tap water for 15 minutes, stained with haematoxylin for 15 minutes, differentiated in 1\% alcohol (3 dips) and blued in 
running tap water for 10 minutes. The slides were then counterstained with $1 \%$ alcohol eosin for 1 minute followed by rapid dehydration in ascending grades of alcohol, cleared in xylene, mounted with DPX and viewed under light microscope and photographed at X400 magnification.

\section{Histochemical examination}

Feulgen's reaction for testicular DNA distribution

- Reagents: IM Hcl, Schiff reagent, potassium metabisulphite, Light green

- Procedure: All sections were brought to water and then rinsed in $\mathrm{n}-\mathrm{Hcl}$ at room temperature for 1 minute. Sections were thereafter placed in $\mathrm{n}-\mathrm{Hcl}$ at $60^{\circ} \mathrm{C}$ for 15 minutes. Sections were rinsed at room temperature for 1 minute and then transefered to Schiff reagent for 45 minutes. They were rinsed in bisulphite solution for three times for 2 minutes per rinse and transferred to distilled water. $1 \%$ light green was used to counterstain the sections for 2 minutes. They were then washed in water, dehydrated through graded alcohols to xylene, mounted and viewed under light microscope and photographed at X400 magnification.

\section{Statistical analysis}

One way analysis of variance (ANOVA) and Post-Hoc Least Significant Difference (LSD) tests were used to analyze the qualitative data from the study. Results are represented as Mean \pm Standard Error of Mean (SEM). Differences between the experimental groups with p-value $<0.05$ was considered statistically significant.

\section{Results}

\section{Morphological observation}

Morphological observation from the study shows an observable significant $(\mathrm{p}<0.5)$ increase in the final mean body weight when compared to the initial body weight. The final body weight in the control animals $(133.75 \pm 2.32)$ was significantly $(\mathrm{p}<0.05)$ higher than its initial body weight $(118.40 \pm 1.20)$. However, the mean final body weights of the low dose group $(151.75 \pm 2.05)$ and high dose group (169.25 \pm 2.37 ) were significantly $(\mathrm{p}<0.05)$ higher their initial body weights $(122.80 \pm 1.93)$ and $(126.20 \pm 1.74)$ respectively (Figure 1).

\section{Semen analysis}

- Sperm motility: Result of the study showed revealed the percentage motility in the control group to be (59.80 \pm 0.5$)$, while the low and high dose groups had $(60.00 \pm 0.36)$ and $(60.00 \pm 0.37)$ respectively. Hence there was no observable significant difference between all animals (Figure 2).

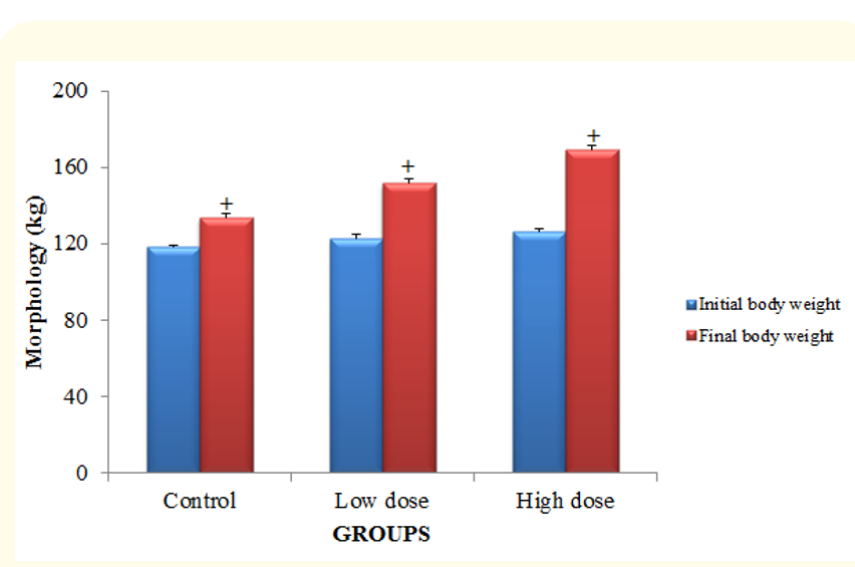

Figure 1: Mean initial and final body weights of experimental animals.

$\mathrm{n}=6$

$+=$ Significantly different from the initial body weight at $\mathrm{p}<0.05$.

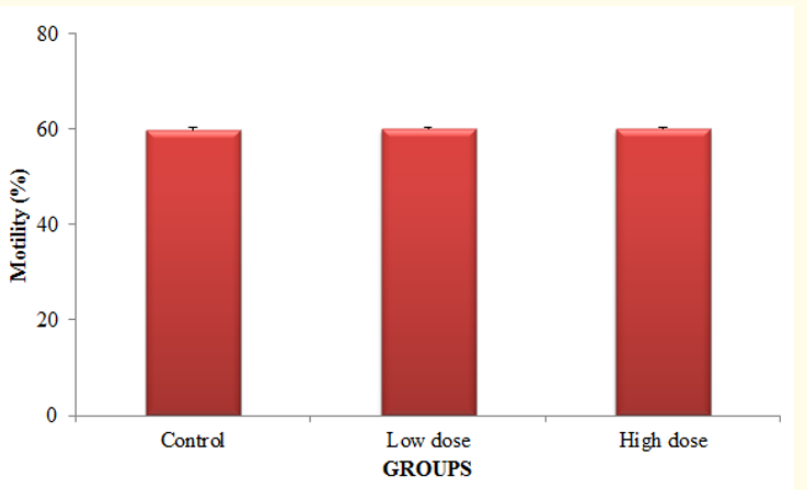

Figure 2: Sperm motility of all experimental animals.

$$
\mathrm{n}=6
$$

- Sperm vitality: The sperm vitality expressed in percentage, was sufficiently $(\mathrm{p}<0.05)$ higher $(70.21 \pm 0.32)$ in the control group when compared to the low dose group (65.34 \pm 0.21 ) and the high dose group ( $65.36 \pm 0.25)$. Meanwhile, there was no significant difference between the low dose and high dose groups (Figure 3)

- $\quad$ Sperm morphology: Similarly, there was a remarkable significant $(\mathrm{p}<0.05)$ reduction in the sperm morphology of animals treated with low dose $(58.8 \pm 1.12)$ and high dose $(59.10 \pm$ 0.60 ) when compared with the control group (63.20 \pm 1.20$)$. The groups treated with the extract showed no meaningful difference in sperm morphology when compared to each other (Figure 4) 


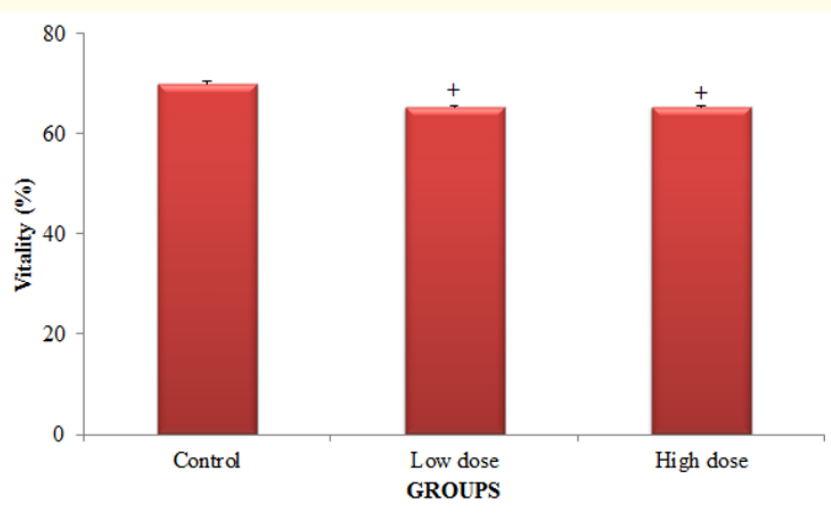

Figure 3: Sperm vitality of all experimental animals.

$$
\mathrm{n}=6
$$

$+=$ Significantly different from the control group @ $\mathrm{p}<0.05$.

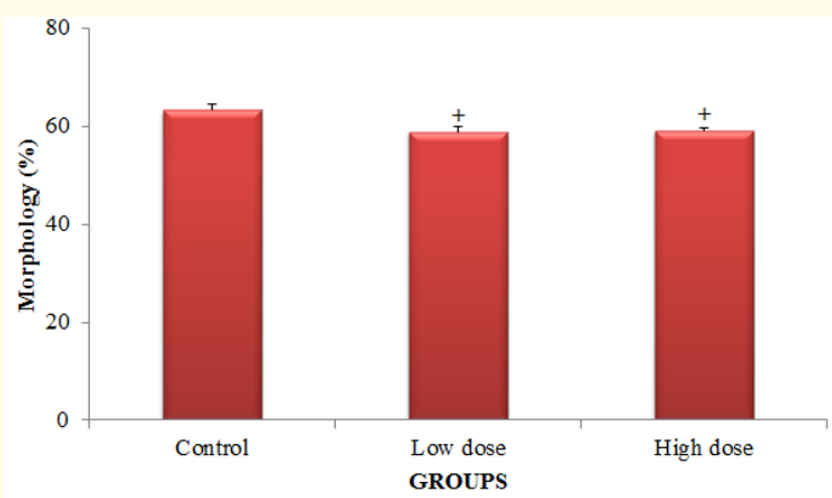

Figure 4: Sperm morphology of all experimental animals.

$$
\mathrm{n}=6
$$

$+=$ Significantly different from the control group @ $\mathrm{p}<0.05$.

\section{Histological observations}

After histological processing of the testes, result of the study reveals a normal histological pattern of the testis of animals in the control group. The seminiferous tubules were normal with normal germinal centres and sertoli cells. Spermatids and interstitial connective tissue were all intact with no observable pathology (Plate $1)$.

Administration of Gnetum africanum at low dose revealed testis with germinal centre, seminiferous tubules with sertoli cell tumours and extensive areas of a prognosis of sclerosis, which caused the sertoli cells to grow larger. The interstitial tissue appeared fibrous (Plate 2).

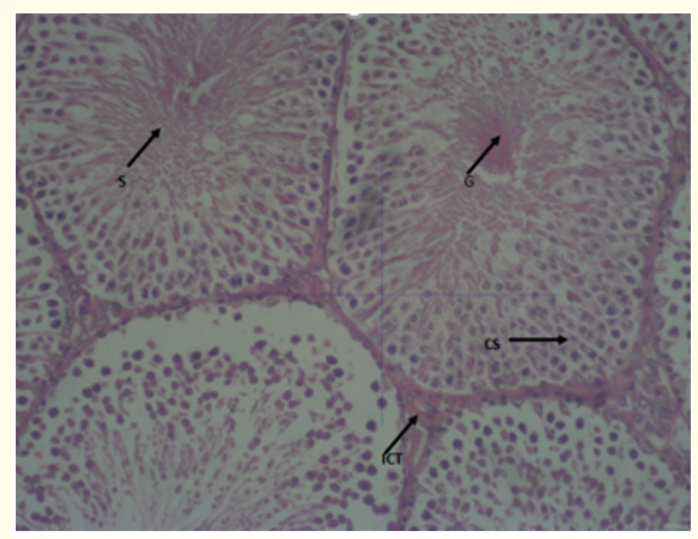

Plate 1: Photomicrograph of the control of the testis showing seminiferous tubules. Germinal center and cells of Sertoli appear normal. Several spermatids and interstitial connective tissue can be seen. H\& E. X400.

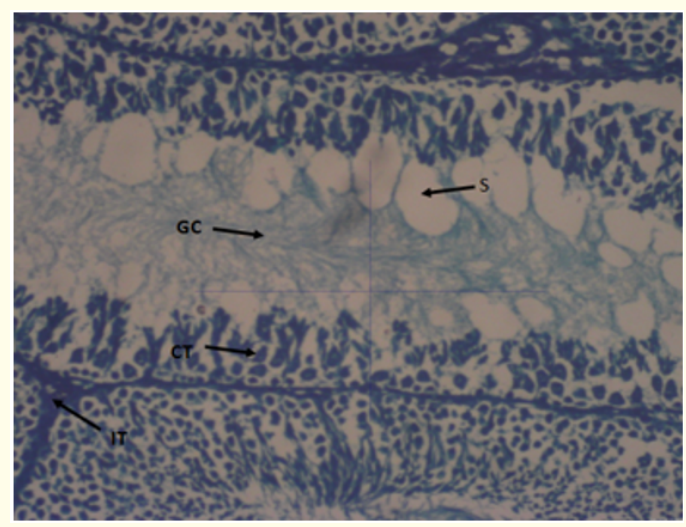

Plate 2: Photomicrograph of the low dose group testis showing a germinal center (GC). Seminiferous tubules with sertoli cell tumor (CT) and extensive areas of a prognosis of sclerosis (S) making the sertoli cells grow larger and the interstitial tissue (IT) appear fibrous. H \& E. X400

The high dose group testes revealed a general testicular regression syndrome which is an indication of testicular infarct (Plate 3).

\section{Histochemical studies}

\section{Deoxyribonucleic acid (DNA) demonstration}

Result from the study revealed testes of animals in the control group with moderately stained magenta colour architecture indicating the presence of DNA (Plate 4). This colour intensity was however maintained in the low dose treated group which also 


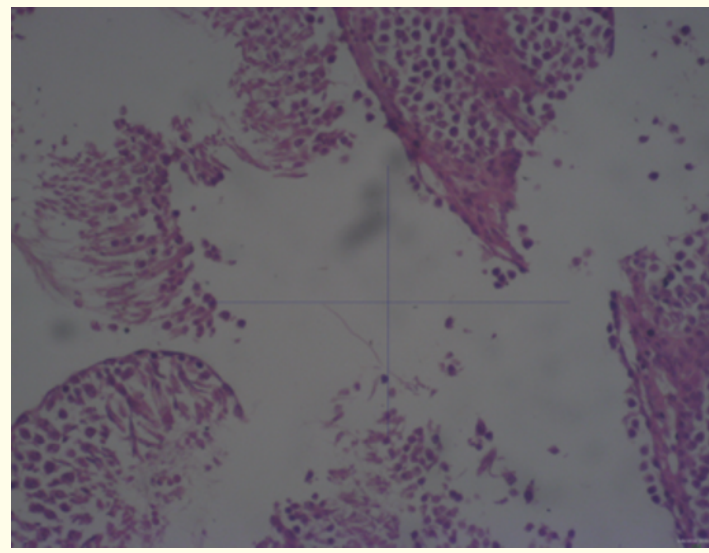

Plate 3: Photomicrograph of the high dose testis showing a general testicular regression syndrome, an indication of testicular infarct. H \& E. X400.

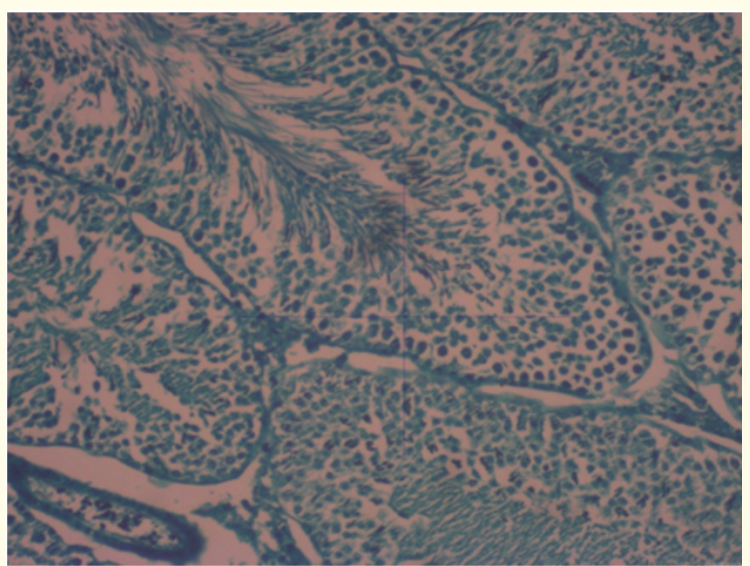

Plate 4: Photomicrograph of the control testis, showing moderately stained architecture. Feulgen Stain. X400.

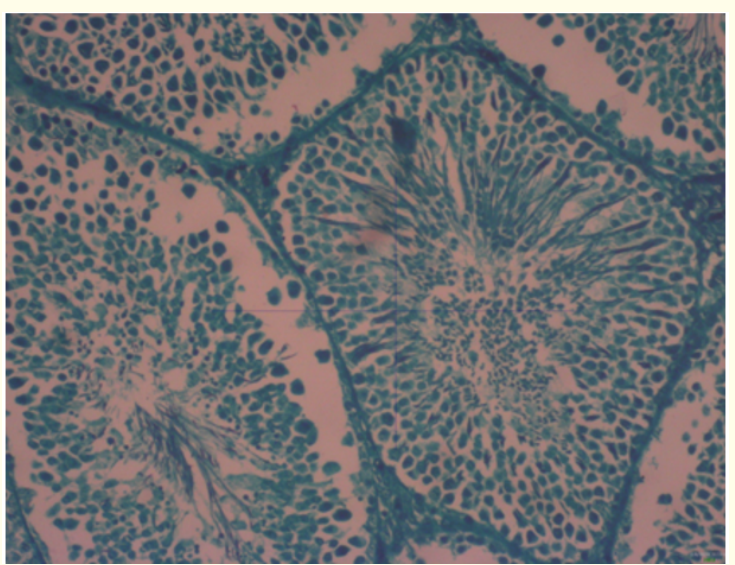

Plate 5: Photomicrograph of the low dose testis showing moderately stained architecture, germinal center with seminiferous tubule and sertoli cell appearing normal. Feulgen stain. X400.

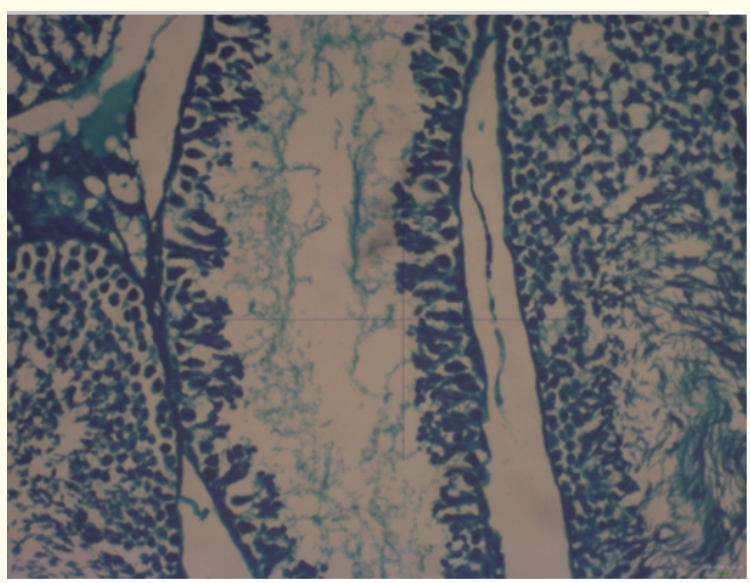

Plate 6: Photomicrograph of the high dose the testis, architecture is deeply stained, prognosis of sclerosis and testicular regression observed. Feulgen Stain. X400.

\section{Discussion}

After administration of Gnetum africanum at various doses, there was a significant $(\mathrm{p}<0.05)$ increase in the final body weigh when compared to the initial body weight. This increase in mean body weight could be as a result of the nutritional value of Gnetum africanum and its high crude fibre content which may also contribute to a reduction in the incidence of certain diseases like colon cancer, coronary heart disease, diabetes, high blood pressure, obesity and other digestive disorders $[8,9]$.

Semen parameters are crucial for effective fertilization process. From the study, there was no significant difference in sperm motility among all the experimental groups. This is suggestive that extract of Gnetum africanum can increase the motility of sperm cells, leading to improved fertility. This result is in consonance with Otteng (1990) who reported that Gnetum africanum leaves contain minerals including magnesium which prevents cardiomyopathy, impaired spermatogenesis and bleeding disorders.

Sperm vitality refers to the percentage of living and healthy sperm cells present in the semen while sperm morphology is the best predictor of fertilization potential (Guzik., et al. 2001). Result from the study reveals a significant decrease in both parameters (sperm vitality and morphology). This could be as a result of increase iron content in Gnetum africanum which is above the required standard stated by FAO/WHO (1988) as stated by Okerulu, and Onyema [10]. It has been observed that excessive iron content may result in defective spermatogenesis, reduced libido and oxidative damage to the testicular tissue and spermatozoa [11]. 
Histological observations revealed the control group showed normal histological pattern of the testis with normal seminiferous tubules bearing normal germinal centres and sertoli cells with intact spermatids and interstitial connective tissue. However, the low dose and high dose group showed observable pathologies. The low dose group showed sertoli cell tumour and extensive areas of a prognosis of sclerosis which caused enlargement of the sertoli cells, while the high dose group revealed a general testicular regression syndrome indicating testicular infarction. This result may be due to the outrageous ironic content in Gnetum africanum leaves as reported by Okerulu and Onyema [10], which can induce oxidative stress leading to testicular damage [11].

Histochemical results showed testes of animals in the control group with moderately stained magenta colour architecture indicating the presence of DNA. This colour intensity was however maintained in the low dose treated group which also showed a moderately stained magenta colour. Meanwhile, in the high dose, the colour intensity was deep showing increase in the DNA content of the testis when compared to the control and low dose group. This effect may be due to the numerous vital minerals found in Gnetum africanum leaves [10].

\section{Conclusion}

From the result of the study, it is suggestive that consumption of Gnetum africanum, although may lead to increase in testicular DNA, may as well cause deleterious effects on the histology of the testes with reduction in semen quality.

\section{Bibliography}

1. Rothwell GW., et al. "Elkinsia gen. nov., a Late Devonian gymnosperm with cupulate ovules". Botanical Gazette. University of Chicago Press. 150.2 (1989): 170-189.

2. Anthony BO., et al. "Phytochemistry and spermatogenic potentials of aqueous extracts of Cissus populnear". The Science World Journal 6 (2010): 2140-2146.

3. Nordqvist C. Infertility: Causes, Diagnosis, Risks, Treatments. Medical News Today. MediLexicon, Intl., 21 (2016).

4. World Health Organization. WHO Laboratory Manual for the Examination and Processing of Human Semen. 5th ed. Geneva: World Health Organization (2012).

5. Anate $\mathrm{M}$ and Akeredolu 0. "Attitude of male partners to infertility management in Ilorin". Nigeria Medical Practitioners 21 (1991): 26-32.
6. Myers JB and Meacham RB. "Androgen replacement therapy in the aging male". Reviews in Urology 5.4 (2003): 216-226.

7. Sargis RM. Overview of the testis (2015).

8. Ekop AS. "Determination of Chemical Composition of Gnetum africanum (Afang) Seed". Pakistan Journal of Nutrition 6 (2007): 40-43.

9. Ogunlade IA., et al. "A Comparative Study of Proximate Composition, Anti-Nutrient Composition and Functional Properties of Pachira glabra and Afzelia Africana Seed Flours". African Journal of Food Science 5 (2011): 32-35.

10. Okerulu IO and Onyema CT. "Comparative Assessment of Phytochemicals, Proximate and Elemental Composition of Gnetum africanum (Okazi) Leaves". American Journal of Analytical Chemistry 6 (2015): 604-609.

11. Eva T., et al. "Iron and Copper in Male Reproduction: a doubleedge sword". Journal of Assisted Reproduction and Genetics 32 (2015): 3-16.

Volume 3 Issue 8 August 2019

(C) All rights are reserved by Kebe E Obeten., et al. 